\title{
NOTES ON HUMAN- HYENA (Hyaena hyaena, Linnaeus 1751) CONFLICT IN JAJARKOT, KALIKOT AND MAHOTTARI DISTRICTS OF NEPAL
}

\section{Shivish Bhandari and Daya Ram Bhusal}

Journal of Institute of Science and Technology

Volume 22, Issue 1, July 2017

ISSN: 2469-9062 (print), 2467-9240 (e)

Editors:

Prof. Dr. Kumar Sapkota

Prof. Dr. Armila Rajbhandari

Assoc. Prof. Dr. Gopi Chandra Kaphle

Published by:

Institute of Science and Technology

Tribhuvan University

Kirtipur, Kathmandu, Nepal 


\title{
NOTES ON HUMAN- HYENA (Hyaena hyaena, Linnaeus 1751) CONFLICT IN JAJARKOT, KALIKOT AND MAHOTTARI DISTRICTS OF NEPAL
}

\author{
Shivish Bhandari ${ }^{1}$ and Daya Ram Bhusal ${ }^{2, *}$ \\ ${ }^{1}$ Himalayan Biodiversity Network, Nepal \\ ${ }^{2}$ Central Department of Zoology, Tribhuvan University, Kathmandu, Nepal \\ "Corresponding E-mail: drbhusal@cdztu.edu.np
}

\begin{abstract}
Striped hyena is one of the large carnivores of the forest and grassland ecosystem. This paper deals with the distribution and human hyena conflict status in Jajarkot, Kalikot, and Mahottari districts of Nepal. Questionnaire and sign survey methods were used to collect information on human-hyena conflict. This study indicated that human hyena conflict was high in the selected district. Eight striped hyenas died in between 2015-2016 due to the human-hyena conflict. Livestock depredation by striped hyena was one of the major reasons of the human-hyena conflicts in Nepal. The goat was the most preyed species by the striped hyena. This study shows that the distribution of striped hyena was recorded from lowland to mid hills region of Nepal. The conservation outreach programs should be formulated to conserve the habitat and maintain the prey population of the striped hyena which would be helpful for long term conservation of the striped hyena in Nepal.
\end{abstract}

Keywords: Striped hyena, Conflict, Conservation, Livestock, Distribution.

\section{INTRODUCTION}

Globally there are four members of the Hyaenidae family; striped hyena, spotted hyena, brown hyena, and aardwolf (Mills \& Hofer, 1998). These magnificent animals are playing an important role for maintaining forest and grassland ecosystem (Mills \& Hofer, 1998; Abi-Said \& Abi-Said, 2007). Historically, striped hyenas were distributed in Sudan, Eritrea, Somalia, Qatar, Kuwait, and the United Arab Emirates (Cunningham, 2004; Mills \& Hofer, 1998) and now it has patchy distribution, extending from north of Africa, including the Sahel, east and northeast Africa south to central Tanzania, through the Middle East and Arabian Peninsula, Turkey, the Caucasus, Central Asia, and the Indian subcontinent (Abi-Said \& Abi-Said, 2007). The abundance, distribution and population structure of the striped hyena in Indian subcontinent are stable and populations are considered to be declining (Singh et al., 2010; Akay et al., 2011; Sharma et al., 2011; Jnawali et al., 2011). However, little is known about its past and present occurrence in Nepal (Mills \& Hofer, 1998). Furthermore, its distribution pattern in Nepal is unknown as well. Striped hyena has been listed as near threatened category by International Union for the
Conservation of Nature (IUCN). The global population size of striped hyena is estimated to be below 10,000 mature individuals (Abi-Said \& AbiSaid, 2007). There are many records of continuous declining of its population and this is attributed to the decrease of its prey population in its natural habitats (Abi-Said \& Abi-Said, 2007; Alam et al., 2015). The other causes for decline of striped hyena population are the habitat degradation, humanhyena conflict (poison, poaching, and persecution), besides depletion of prey population and wildlife diseases (Dejene et al., 2016). Moreover, its conservation threats have to be studied for balancing the forest and grassland ecosystems. Conflict between human and wildlife populations is emerging as a major conservation issue in Nepal. Therefore human-striped hyena conflict is a big issue to save its remaining population in this country. There are large gaps in our knowledge on several aspects of the striped hyena behavior and its ecology such as competition with other carnivores, effect of habitat degradation and climate change. Particularly the population dynamics and ecological niche of striped hyena is urgently needed to document in Nepal. Our study explored notes on distribution information and scenario of human- 
hyena conflict. Furthermore, it opens the ideas for detail scientific studies and conservation of this large carnivore in Nepal.

\section{MATERIALS AND METHODS}

This study was conducted in Jajarkot, Kalikot, and Mahottari districts of Nepal (Figure 1). We employed sign (pugmark, scat and kill study) and questionnaire survey methods (Bhandari et al., 2015; Bhandari \& Chalise, 2016; Alam \& Khan
2015). We followed published guidelines (Baral \& Shah, 2008; Jnawali et al., 2011; Alam \& Khan, 2015; Bhandari et al., 2015) for striped hyena's sign and identification. Questionnaires were asked with the key persons (community forest staffs and users) to collect current information of the striped hyena and 100 persons were asked during the survey. Moreover, we also surveyed literatures (reports, articles and books) to get current and past information on the striped hyena in Nepal.

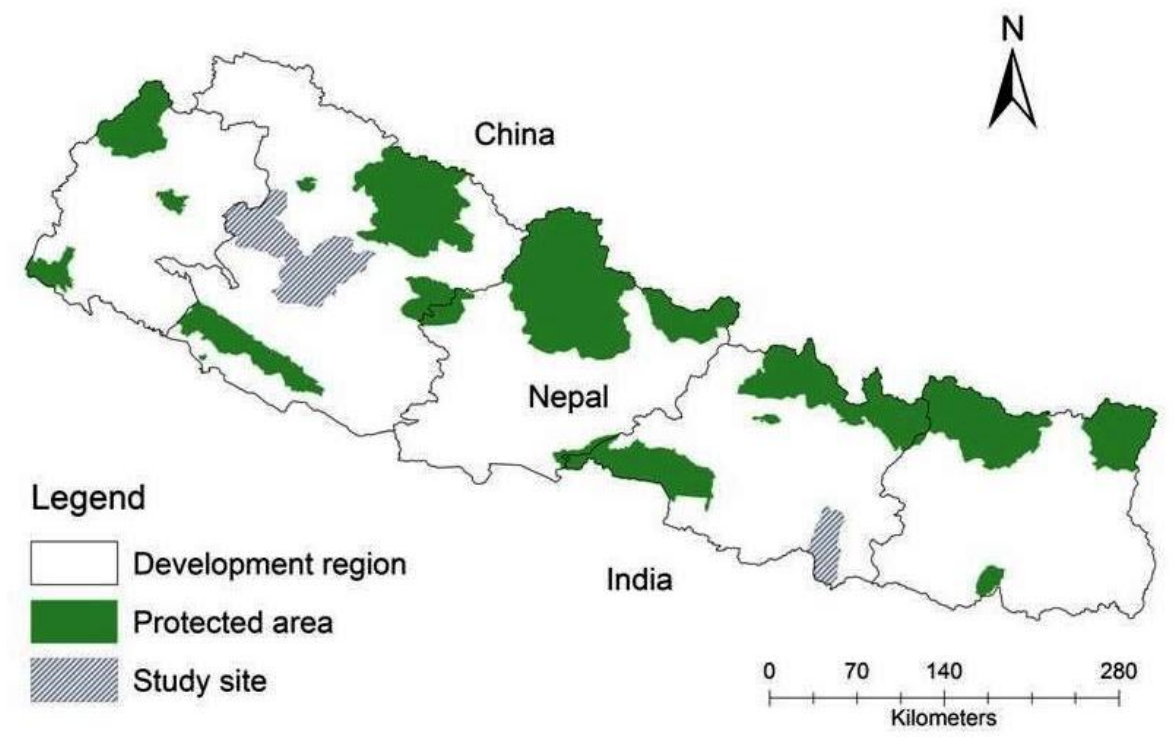

Fig. 1. Study site location.

\section{RESULTS}

Human-striped hyena conflict was found very high in the mid hill region such as Jajarkot and Kalikot districts of Western, Nepal. Six striped hyenas were killed in between 2015-2016 due to human-hyena conflict. Moreover, in the Mahottari, two striped hyenas were killed using poison by the local people in between 2015-2016 (Table 1). The major reason for human-striped hyena conflict was the livestock predation by striped hyena. Most of the respondents argued that, goat was the most preyed animal and dog was least preyed animal by the striped hyena (Figure 2).
Distribution range of striped hyena in Nepal was found wide. It was distributed from lowland (around $100 \mathrm{~m}$ ) including protected areas and few other places to the mountainous region (up to 1750 $\mathrm{m}$ above the sea level) (Table 2). The striped hyena signs were recorded from mid hills (mountainous regions) the Jajarkot and Kalikot districts. Altogether, 35 signs of striped hyena were found from Jajarkot Kalikot and Mahottari districts (Figure 3). Its habitats continue to shrink and fragment due to the anthropogenic pressure and human-hyena conflict in its distributed range of Nepal.

Table 1. Loss of striped hyena in the study site.

\begin{tabular}{|l|c|c|l|l|}
\hline \multirow{2}{*}{ Location } & \multicolumn{2}{|c|}{ Number of died hyena } & \multirow{2}{*}{ Reason } & \multirow{2}{*}{ Remarks } \\
\cline { 2 - 3 } & Year 2015 & Year 2016 & & \\
\hline Jajarkot & 1 & 3 & Human-hyena conflict & Poisoned \\
\hline Kalikot & & 2 & Unknown & ------- \\
\hline Mahottari & 1 & 1 & Human-hyena conflict & Poisoned \\
\hline
\end{tabular}




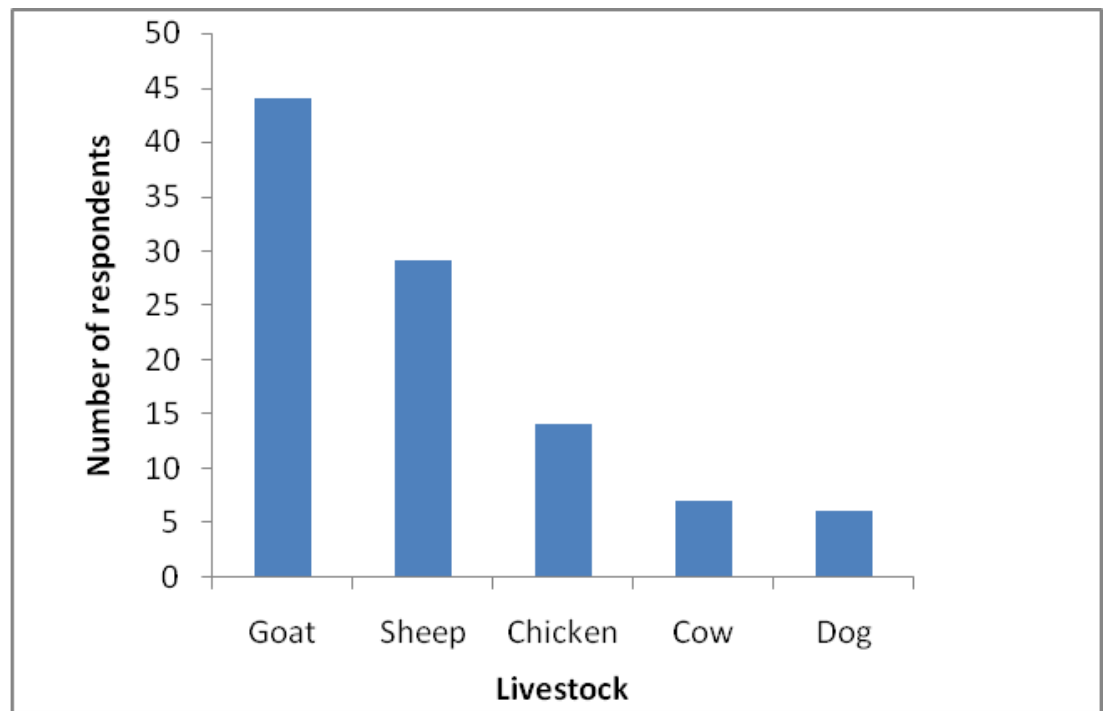

Fig. 2. Livestock preyed by striped hyena in the study site $(n=100)$.

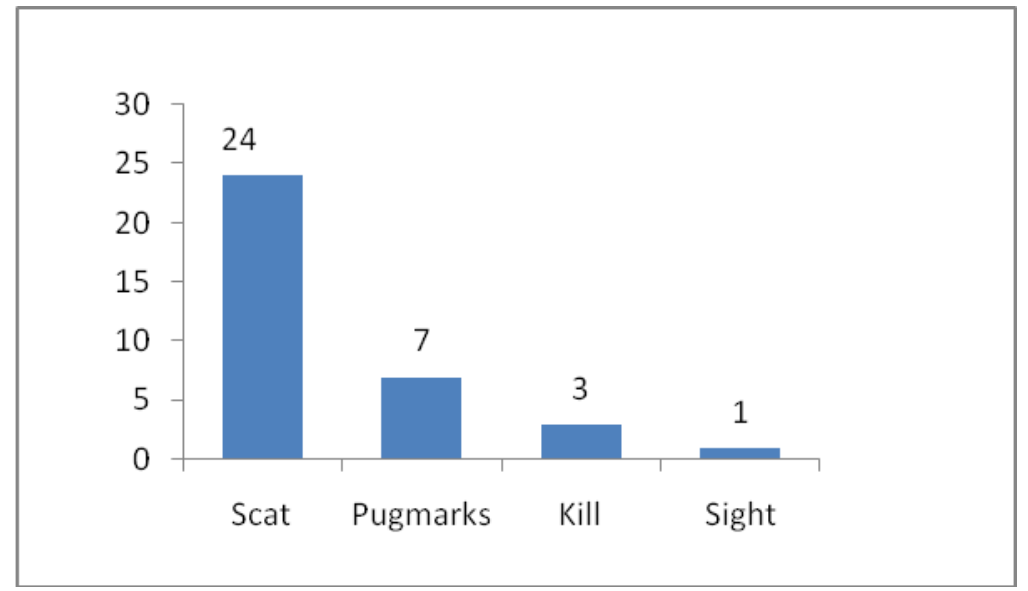

Fig. 3. Signs of the striped hyena in the study site.

Table 2. Records of striped hyena in different regions of Nepal.

\begin{tabular}{|l|l|l|}
\hline Regions & Methods used to survey & References \\
\hline Lowland $(<1000 \mathrm{~m})$ & Sign survey & $\begin{array}{l}\text { Bhandari } \text { et al. } 2015 \\
\text { Bhandari and Chalise } 2016\end{array}$ \\
\hline Mountainous region $(>1000 \mathrm{~m})$ & Sign survey & $\begin{array}{l}\text { Majupuria and Majupuria } 2006 \\
\text { Our study }\end{array}$ \\
\hline
\end{tabular}

\section{DISCUSSION}

Anthropogenic pressure, human population growth coupled with expansion of agriculture resulted in habitat degradation through the loss of vegetation cover of the country (Mills and Hofer, 1998; Kruuk, 1976; Alam et al., 2014). In this study, the major threats for the hyena were hunt and deforestation. However, higher level of human hyena conflict recorded in mid hill district (Jajarkot) is probably due to lack of conservation awareness and mitigation program for this species.

Comparing to eastern part of Ethiopia (Dajene et al., 2016), existence of large population density of spotted hyena in highly human populated areas was 
attributed to the availability of livestock prey and domestic waste disposal (Dejene et al., 2016). Similar situation may be prevalent in populated districts of Nepal but further study is needed to focus on the correlation of human population, livestock situation and population of striped hyena. The high killing of livestock (goat) in our study sites increases human-hyena conflict. Studies analyzing human wildlife conflict in many parts of the world showed that the rate of tolerance among local communities toward predators mostly depends on the degree of predation on their domestic animals (Kolowski \& Holekamp, 2006; Holmern et al., 2007).

Therefore, human-hyena conflict is one of the major challenges to save the remaining population in Nepal. Authors, Frank (1998 cited in Dejene et al., 2016), Ogada et al. (2003) and Dejene et al. (2016) suggested that livestock loss by wildlife as a cause for human wildlife conflict and wildlife is accountable for the loss of 3\% of livestock per year (Jackson \& Nowell, 1996). Our questionnaire survey also indicated the low awareness status of the local people about conservation of wildlife including striped hyena. Bhandari \& Chalise (2016) reported that people's perceptions toward striped hyenas and its conservation were overall positive in lowland districts of the eastern Nepal.

\section{CONCLUSION}

To minimize the hyena -human conflict in Jajarkot, Kalikot and Mahattori district, suitable mitigation and outreach programs should be conducted in local areas. In most conflicting sites compensation programs should be launched that would be helpful to save striped hyena's population in Nepal. There is large gap in our knowledge on several aspects of the striped hyena behavior and its ecology such as competition with other carnivores, effect of habitat degradation and climate change. The population dynamics and ecological niche of striped hyena is urgently needed to be documented in Nepal. Moreover, the prey population should be conserved and habitat destruction should be controlled.

\section{ACKNOWLEDGEMENTS}

We thank to "The Rufford Foundation" UK for the funding a part of this project. We thanked to the Himalayan Biodiversity Network-Nepal for the equipment and field supports. We are grateful to the Community Forests Members-Jajarkot, Kalikot and Mahottari Districts.

\section{REFERENCES}

Abi-Said, M. R. and Abi-Said, M. D. (2007). Distribution of the striped hyena (Hyena hyena syriaca Matius, 1882) (Carnivora: Hyaenidae) in urban and rural areas of Lebanon. Zoology of the Middle East, 42 (1): 3-14.

Akay, A. E.; Inac, S. and Yildirim, I. C. (2011). Monitoring the local distribution of striped hyenas (Hyena hyena L.) in the Eastern Mediterranean Region of Turkey (Hatay) by using GIS and remote sensing technologies. Environmental Monitoring and Assessment, 181: $145-455$.

Alam, M. S. and Khan, J. A. (2015). Food habits of striped hyena (Hyena hyena) in a semi-arid conservation area of India. Journal of Arid Land, 7 (6): 860-866.

Alam, M. S.; Khan, J. A. and Pathak, B. J. (2015). Striped hyena (Hyena hyena) status and factors affecting its distribution in the Gir National Park and Sanctuary, India. Folia Zoological, 64: 32-39.

Baral, H. S. and Shah, K. B. (2008). Wild mammals of Nepal. Himalayan Nature, Kathmandu. Nepal. pp.188.

Bhandari, S. and Chalise, M. K. (2016). People's attitudes toward striped hyena (Hyena hyena Linnaeus, 1758) (Mammalia: Carnivora: Hyaenidae) conservation in lowland Nepal. Journal of Threatened Taxa, $\mathbf{8}$ (9): 9125-9130.

Bhandari, S.; Rijal, R. and Khanal, S. (2015). Status of striped hyena (Hyena hyena Linnaeus, 1758) and their conservation approaches in Rautahat and Sarlahi forests, Nepal. Journal of Natural History Museum, 29: 49-59.

Cunningham, P. L. (2004). Checklist and status of the terrestrial mammals from the United Arab Emirates. Zoology of the Middle East, 33 (1): 7-20.

Dejene, S. W.; Dechassa, N. and Reddy, R. U. (2016). Coexistence of human and hyena and associated impacts in Haramaya district of Eastern Ethiopia. International Journal of Biodiversity and Conservation, 8 (1): 1-7.

Holmern, T.; Nyahongo, J. W. and Roskaft, E. (2007). Livestock loss caused by predators outside the Serengeti National Park, Tanzania. Biological Conservation, 135: 518-542. 
Jackson, P. and Nowell, K. (1996). Problems and possible solutions in management of felid predators. Journal of Wildlife Research, 1: 304-314.

Jnawali, S. R.; Baral, H. S.; Lee, S.; Acharya, K. P.; Upadhyay, G. P.; Pandey, M.; Shrestha, R.; Joshi, D.; Lamichhane, B. R.; Griffiths, J.; Khatiwada, A. and Amin, R. (2011). The Status of Nepal Mammals: The National Red List Series. Department of National Parks and Wildlife Conservation, Kathmandu, Nepal, pp. 276.

Kolowski, J. M. and Holekamp, K. E. (2006). Spatial, temporal, and physical characteristics of livestock depredations by large carnivores along a Kenyan reserve border. Biological Conservation, 128: 529-541.

Kruuk, H. (1972). The Spotted Hyena: A study of predation and social Behavior. University of Chicago Press, Chicago, pp. 352.

Majupuria, T. K. and Majupuria, R. K. (2006). Wildlife and protected areas of Nepal. Craftsman Press Ltd, Bangkok, Thailand, pp. 549.
Mills, M. G. L and Hofer, H. (1998). Hyenas. Status Survey and Conservation Action Plan, IUCN/SSC Hyena Specialist Group. IUCN, Gland, Switzerland and Cambridge, UK, pp. 154.

Ogada, M. O.; Woodroffe, R.; Oguge, N. O. and Frank, L. G. (2003). Limiting depredation by African carnivores: the role of livestock husbandry. Conservation Biology, 17: 1521-1530.

Sharma, G.; Vijay, P.; Rajpurohit, I. S. and Ram, C. (2011). Ecobehaviour study and status of striped hyena (Hyena hyena Linnaeus, 1758) in South Western Rajasthan, India. Journal of Evolutionary Biology Research, 3 (4): 44-46.

Singh, P.; Gopalaswamy, A. M. and Karanth, K. U. (2010). Factors influencing densities of striped hyenas (Hyena hyena) in arid regions of India. Journal of Mammalogy, 91 (5): 1152-1159. 